\title{
Decrease Polyphenols, Ethanol, Lactic Acid, and Acetic Acid during Fermentation with Addition of Cocoa Beans Innoculum
}

\author{
Mulono Apriyanto, M Chairul Basrun Umanailo
}

\begin{abstract}
The research objectives were: 1) to know the composition of cocoa bean pulp as substrate for fermentation; 2) evaluate the effect of variation of cocoa seed fermentation technique on microbial population. Stages of research conducted are as follows (1) testing the composition and water content of cocoa bean pulp as a fermentation substrate. (2) Fermented cocoa beans with 3 variations of fermentation technique ie first treatment without addition of inoculum (control), both using inoculum S. cerevisiae (FNCC 3056), L. lactis (FNC 0086) and A. aceti (FNCC 0016), respectively - about 108 $\mathrm{cfu} / \mathrm{g}$ is given simultaneously at the beginning of fermentation (IA). (3) gradual inoculum administration of yeast at the beginning of fermentation, lactic acid bacteria at 24 hours and acetic acid bacteria at $48 \mathrm{~h}$ with microbial population equal to second treatment (IB). Fermentation is carried out for 120 hours. Temperatures are adjusted during fermentation, respectively 35 oC (first 24 hours), 45 oC (24 second hours), 55 oC (24 hours three) and 35 oC (last 48 hours). The third stage of fermented cocoa beans from the three treatments was roasted and analyzed for their volatile compounds. The results showed that during the fermentation of cocoa beans showed that all treatments increased the ethanol kosentarsi in line with the increasing population of S. cerevisiae at the beginning of fermentation. Next L. lactis increased followed by lactic acid, at the end of A. aceti fermentation increased followed by acetic acid. From the results of this study it can be concluded that the rehydration of cocoa bean pulp can improve the composition of pulp as fermentation substrate. The microbial population indicated that there was a microbial succession shown in the gradual addition of inoculum treatment.
\end{abstract}

Keywords: cocoa beans, fermentation, inoculum, ethanol, lactic acid and acetic acid

\section{INTRODUCTION}

Production of dried cocoa beans from community plantations in general does not use a fermentation process either naturally or by the addition of an inoculum. In general, cocoa farmers only soak fresh cocoa beans in water in an effort to help remove pulp and put them in the sun. Dried cocoa beans with unknown water content, sold without regard to quality both in terms of water content and the condition of the dried beans are called asalan cocoa beans. Fermentation is an important factor in processing cocoa beans, especially in the formation of flavor precursor compounds. Fermentation of fresh cocoa beans consists of 2 stages: the first stage begins with the removal of pulp from the surface of the seeds and the second hydrolytic reaction in the seed cotyledons. Changes in the type and number of microbes during the fermentation of cocoa beans are better known as microbial succession. In the initial stages of fermentation the presence of microbes is dominated by yeast, followed by lactic acid bacteria and the end of fermentation by acetic acid bacteria[2][3]. The microbial activity produces ethanol, lactic acid and acetic acid during fermentation followed by an increase in the temperature of the fermentation environment. Alcohol and acetic acid are diffused into the cocoa beans and followed by an increase in temperature which results in the death of the beans (cannot germinate). The process of cocoa fermentation generally takes place naturally assisted by microbes from the air lasting for 6 days and the first reversal is done on the second day and then carried out every 24 hours [4]. S. cerevisiae has several advantages such as excellent growth, tolerance to ethanol, and pectinolytic activity and resistance to low $\mathrm{pH}$. Lactobacillus $s p$ found in fresh cocoa beans fermentation media is L. lactis, with the advantages of being more competitive, more tolerant of acids and ethanol and resistant to environmental conditions with more oxygen. Acetic acid bacteria are dominated by A. aceti with the ability to grow at ethanol concentrations up to $6.0 \%$, temperature $45 \circ \mathrm{C}$ and at $\mathrm{pH} 3.5$ and ethanol is oxidized to acetic acid and further converted to acetic acid into $\mathrm{CO} 2$ and water [5]. This study aims to determine the succession of microbes and changes in the concentration of ethanol, lactic acid and acetic acid during fermentation.

\section{MethOD}

The type of cocoa fruit (bulk cacao) was obtained from the village of Kotabaru, Indragiri Hilir, Riau with the characteristics of fruit length $\pm 15 \mathrm{~cm}$, diameter $\pm 8 \mathrm{~cm}$, optimal ripe fruit skin orange, the number of seeds per pod \pm 35 pieces of seeds. Inoculum S. cerevisiae (FNCC 3056), L. lactis (FNC 0086) and A. aceti (FNCC 0016) were obtained from the microbiology laboratory of the Center for Food and Nutrition Studies at Gadjah Mada University. Acetone $80 \%$, BSA (bovient serum albumin), phosphate buffer, acetic acid, tricloroacetic acid, $\mathrm{HCl}$, buffer solution $\mathrm{pH} \mathrm{4,} \mathrm{pH} 7$ and $\mathrm{pH} \mathrm{9,} \mathrm{hexan,} \mathrm{Folin-}$ Ciocalteu solution, $\mathrm{Na} 2 \mathrm{CO} 3$. Controlled fermentation with the addition of microbial inoculums and incubator temperature regulation by control treatment refers to [6]. The hydrated dry cocoa beans used at this stage are selected. Rehydration cocoa beans as much as 100 grams fermented for $5 \times 24$ hours with three variations of treatment: a). without the addition of an inoculum called control, b) with the addition of $S$. cerevisiae inoculum (FNCC 3056), L. lactis (FNC 0086) and A. aceti (FNCC 0016) simultaneously at the beginning of fermentation with a population of $108 \mathrm{cfu} / \mathrm{g}$ respectively, and c) by the gradual addition of microbial inoculums as follows: $S$. cerevisiae (FNCC 3056) at the beginning of the first 24 hours, L. lactis (FNC 0086) at the beginning of the second 24 hours and A. aceti (FNCC 0016) at the beginning of the third 24 hours, each with a population of $108 \mathrm{cfu} / \mathrm{g}$. Fermentation is carried out sequentially with a controlled temperature: $35 \pm$ $0.10 \mathrm{C}$ at the beginning of the first 24 hours, $45 \pm 0.1 \mathrm{oC}$ at the beginning of the second 24 hours, $55 \pm 0.10 \mathrm{C}$ at the beginning of the third 24 hours and $35 \pm 0.10 \mathrm{C}$ at the beginning of 24 fourth hour to 120th hour. Total fermentation time is 120 hours. Testing the number of $\mathrm{S}$. cerevisiae, L. lactis and $\mathrm{A}$. aceti using the pour plate count method [7], the concentration of ethanol, lactic acid and acetic acid (the method of Kresnowati, Suryani, \& Affifah, 2013). The experimental design was carried out using a Completely Randomized Design (CRD). All data were analyzed statistically by way of anova at a significance level of 
$95 \%$ if significantly different followed by a LSD test (least Significant different) using the SPSS 17 program.

\section{Results AND Discussion}

\subsection{Early Microbial Population}

The results showed that during the drying of the cocoa beans there was a decrease in the composition of the dried cocoa beans and the population of $S$. cerevisiae, L. lactis and $A$. aceti, in order to be able to carry out the fermentation process of the dried cocoa beans pulp had to meet the requirements as a substrate. The decline in $\mathrm{S}$. cerevisiae population due to water in the pulp of the cocoa beans evaporated so that the growth of $\mathrm{S}$. cerevisiae was disrupted and caused cell death. L. lactis has decreased because of the drying temperature decreases the free water content so that bacteria cannot grow optimally. Bacterial growth requires more free water than yeast. In the process of drying Aw down, meaning that the remaining free water is not sufficient for growth needs, even though the pulp provides the necessary nutrients. The drying process evaporates water in the pulp as well as all alcohols from sugar refinement by $S$. cerevisiae resulting in an undeveloped population of $A$. aceti. The population of $S$. cerevisiae, L. lactis and A. aceti were respectively $4.5 \times 10^{5} \mathrm{cfu}$ $/ \mathrm{g}, 5.7 \times 10^{6} \mathrm{cfu} / \mathrm{g}$ and $5.2 \times 10^{4} \mathrm{cfu} / \mathrm{g}$ (cfu = Colony Forming Unit). The results of this study indicate that the dried cocoa beans have $S$. cerevisiae, $L$. lactis and $A$. aceti populations, these populations have not been sufficient to continue the fermentation of cocoa beans developed at the beginning of fermentation, adjusted to the research of [8], and [9]. Populations of S. cerevisiae, L. lactis and A. aceti found in fresh pulp cocoa bean and pulp dried cocoa bean are presented in Table 1.

Table 1. Populations of S. cerevisiae, L. lactis and A. aceti in fresh cocoa bean pulp and dried cocoa bean pulp.

\begin{tabular}{lcc}
\hline \multicolumn{1}{c}{ Microbes } & $\begin{array}{c}\text { Pulp fresh cocoa } \\
\text { bean } \\
\text { (cfu/g) }\end{array}$ & $\begin{array}{c}\text { Pulp dried cocoa } \\
\text { bean } \\
\text { (cfu/g) }\end{array}$ \\
\hline S. cerevisiae & $4,5 \times 10^{6}$ & $4,5 \times 10^{5}$ \\
L. lactis & $4,2 \times 10^{7}$ & $5,7 \times 10^{6}$ \\
A. aceti & $4,6 \times 10^{5}$ & $5,2 \times 10^{4}$ \\
\hline
\end{tabular}

\subsection{Microbial Succession}

The results of this study indicate that in the control treatment of $S$. cerevisiae, $L$. lactis and $A$. aceti populations at the beginning of fermentation, 5.55, 6.66 and $4.65 \mathrm{log}$ (cfu / g) respectively. The results of statistical analysis evaluating fermentation results through chemical and microbiological changes with control treatment, IA and IB are presented in Table 2.

Table 2. Results of statistical analysis of S. cerevisiae, $L$. lactis, $A$. aceti, ethanol, lactic acid, acetic acid, total polyphenol and hydrophobic amino acids.

\begin{tabular}{|c|c|c|c|}
\hline \multirow[t]{2}{*}{ Parameter } & \multicolumn{3}{|c|}{ Treatment } \\
\hline & Control & IA & IB \\
\hline $\begin{array}{l}\text { S. cerevisiae }(\log \\
\mathrm{cfu} / \mathrm{g})\end{array}$ & $4,93 \pm 0,35 a$ & $5,86 \pm 0,95 a$ & $5,66 \pm 0,05 a$ \\
\hline L. lactis (log cfu/g) & $6,90 \pm 0,37 a$ & $8,6 \pm 0,46 b$ & $8,55 \pm 0,66 b$ \\
\hline A. aceti (log cfu/g) & $5,57 \pm 0,27 a$ & $7,78 \pm 0,48 b$ & $4,67 \pm 0,81 b$ \\
\hline Ethanol (\%) & $1,81 \pm 0,50 a$ & $1,93 \pm 0,57 a$ & $1,94 \pm 0,6 a$ \\
\hline Lactic acid (\%) & $2,64 \pm 0,37 a$ & $2,47 \pm 0,39 a$ & $2,54 \pm 0,40 a$ \\
\hline Acetic acid (\%) & $3,09 \pm 0,58 a$ & $3,25 \pm 0,62 a$ & $3,43 \pm 0,70 a$ \\
\hline
\end{tabular}

Note: The different letters behind the numbers in the same line show the real difference in $p<0.05$. The average results of 2 replications with 3 replications analysis In the control treatment at the beginning of fermentation, the concentration of ethanol, lactic acid and acetic acid was entirely $0 \%$. At 24 hours of fermentation changes in the population of $S$. cerevisiae, $L$. lactis and A. aceti were $7.24 ; 6.70$ and $6.71 \log (\mathrm{cfu} / \mathrm{g})$. The concentrations of ethanol, lactic acid and acetic acid were $4.83,1.83$ and $1.53 \%$, respectively. At 48 hours of fermentation, the population of S. cerevisiae, L. lactis and A. aceti were 5.88, 8.66 and $6.64 \log (\mathrm{cfu} / \mathrm{g})$, respectively. The concentrations of ethanol, lactic acid and acetic acid were $2.63,3.44$ and $2.35 \%$, respectively. At 72 hours fermentation of S. cerevisiae, L. lactis and A. aceti populations were 4.23, 8.43 and $6.11 \log (\mathrm{cfu} / \mathrm{g})$, respectively. The concentrations of ethanol, lactic acid and acetic acid were 1.02, 4.03 and 3.46\%, respectively. The results of one-way ANOVA statistical analysis showed that the average population of $S$. cerevisiae in control, IA and IB were 4.93, 5.86 and $5.66 \mathrm{log}$ (cfu / g) and were not significantly different $(p \leq 0,05)$. It can be assumed that controlling environmental temperature is ideal for the growth of S. cerevisiae. The average population of L. lactis showed that control treatment, inoculum addition simultaneously and gradually were $6.90,8.6$ and $8.55 \mathrm{log}(\mathrm{cfu} / \mathrm{g})$ and control treatments showed significantly different from other treatments. . The average population of $A$. aceti showed that the control treatment, inoculum addition simultaneously and gradually were $5.57,7.78$ and $8.74 \mathrm{log}(\mathrm{cfu} / \mathrm{g})$. Statistical test results showed that the control treatment was significantly different $(p=0.05)$ to the treatment of inoculum addition simultaneously and gradually. Changes in the population of $S$. cerevisiae, $\mathrm{L}$. lactis and $\mathrm{A}$. aceti that produce control treatments in accordance with the results of the research of [8] and [10], who have studied the growth of yeast, lactic acid bacteria and acetic acid bacteria during the fermentation of fresh cocoa beans. Anova analysis results of this study showed that the average production of ethanol, lactic acid and acetic acid during fermentation was not significantly different $(p \leq 0.05)$ according to the results of [7] studies that had studied the microbial ecology of cocoa bean fermentation in Indonesia. If it is observed that the concentration of ethanol, lactic acid and acetic acid during fermentation in the control treatment is still relatively low, it can be suspected that the low concentration of ethanol, lactic acid and acetic acid is caused by the population and activity of S. cerevisiae, L. lactis and A. aceti are low. The low population and activity of S. cerevisiae can be caused by temperature and $\mathrm{pH}$ conditions that are not ideal, in line with the results of [11] that the optimum temperature and $\mathrm{pH}$ conditions for polygalaturonase (PG) enzyme activity will occur depolymerization of cocoa bean pulp. The results of this study on the treatment of the addition of S. cerevisiae inoculum (FNCC 3056), L. lactis (FNCC 0086) and A. aceti (FNCC 0016) simultaneously at the beginning of fermentation showed that the population of $S$. erevisiae, $L$. lactis, and A. aceti started fermentation were 8.28, 8.58 and $8.57 \log (\mathrm{cfu} / \mathrm{g}$ ), respectively. The concentration of ethanol, lactic acid and acetic acid produced higher than the control treatment can be suspected that the addition of inoculums increases the population of S. cerevisiae, L. lactis and A. aceti by $108 \mathrm{cfu} / \mathrm{g}$. After 24 hours of fermentation there is an increase in fermentation temperature and environmental $\mathrm{pH}$ fermentation results in optimum conditions for PG enzyme activity and more ethanol is produced so conditions are not 
suitable for $S$. cerevisiae and their roles are replaced by $\mathrm{L}$. lactis. After 48 hours the fermentation of sugar substrate has been relatively low, the aeration is getting better and the ethanol concentration is relatively high, the $\mathrm{pH}$ of the pulp getting smaller makes the ideal conditions for $A$. aceti. The further relationship of $\mathrm{S}$. cerevisiae, L. lactis and $\mathrm{A}$. aceti populations to the concentration of ethanol, lactic acid and acetic acid of cocoa beans in the control during fermentation is presented in Figure 1.

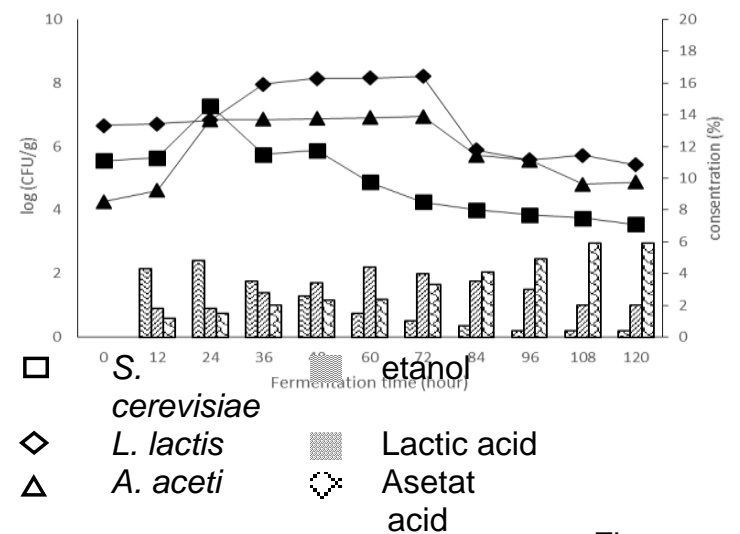

Figure 1.

Relationship of S. cerevisiae, L. lactis and A. aceti populations to the concentration of ethanol, lactic acid and acetic acid during the fermentation of cocoa beans as a result of control treatment. Initial (0) - 24 hours incubator temperature fermentation $35^{\circ} \mathrm{C}, 24$ - 48 hours fermentation incubator temperature $45^{\circ} \mathrm{C}, 48$ - 72 hours fermentation incubator temperature $55^{\circ} \mathrm{C}$ and 72 - 120 hours fermentation incubator temperature $35^{\circ} \mathrm{C}$. At 24 hours fermentation of S. cerevisiae, L. lactis, A. aceti populations respectively $12.41,8.39$ and 8.38 $\log (\mathrm{cfu} / \mathrm{g}$ ), an increase in the population of S. cerevisiae from the beginning of fermentation. At 48 hours of fermentation of S. cerevisiae, L. lactis, A. aceti populations, respectively 5.88 , 11.82 and $8.82 \log (\mathrm{cfu} / \mathrm{g}$ ), the highest L. lactis population occurred at 48 hours of fermentation. At 72 hours of fermentation of S. cerevisiae, L. lactis and A. aceti populations, respectively $4.23,9.11$ and $10.72 \log (\mathrm{cfu} / \mathrm{g}$ ), the highest $A$. aceti population occurred here. Furthermore, the population of S. cerevisiae, L. lactis and A. aceti showed a decrease respectively, 2.5, 6.39 and $5.45 \mathrm{log}$ (cfu / g).

If it is reviewed that the concentration of ethanol, lactic acid and acetic acid shows successively at the beginning of fermentation, that is $0 \%$. At 24 hours of fermentation, concentrations of ethanol, lactic acid and acetic acid were produced, which were $5.23,1.433$ and $1.87 \%$, respectively. At 48 hours of fermentation, concentrations of ethanol, lactic acid and acetic acid were produced, which were 3.02, 3.46 and $2.05 \%$, respectively. At 72 hours fermentation showed concentrations of ethanol, lactic acid and acetic acid, respectively $1.35,3.64$ and $3.54 \%$. At the end of the fermentation the reduction of ethanol concentrations of lactic acid and acetic acid were $0.33,1.82$ and $6.32 \%$, respectively.

The relationship between $S$. cerevisiae, L. lactis and $A$. aceti populations on ethanol, lactic acid and acetic acid concentrations in the inoculum addition treatment is simultaneously presented in Figure 2.

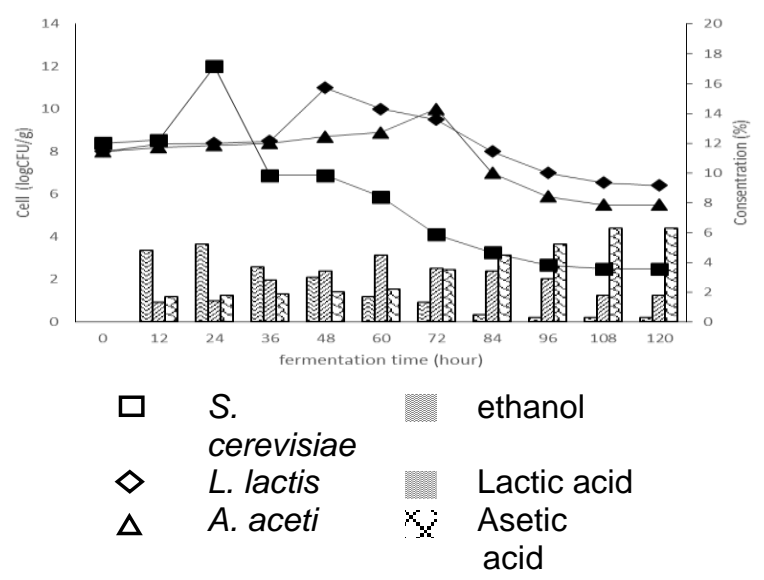

Figure 2.

Relationship of S. cerevisiae, L. lactis and A. aceti populations to the concentration of ethanol, lactic acid and acetic acid during the fermentation of cocoa beans resulting from the inoculum addition treatment simultaneously. Initial (0) - 24 hours incubator temperature fermentation $35^{\circ} \mathrm{C}, 24$ 48 hours

$\begin{array}{llll}\square & \begin{array}{l}\text { S. } \\ \text { cerevisiae }\end{array} & & \text { ethanol } \\ \diamond & \text { L. lactis } & & \text { Lactic acid } \\ \Delta & \text { A. aceti } & \text { Asetic } \\ & & & \text { acid }\end{array}$

fermentation incubator temperature $45^{\circ} \mathrm{C}, 48$ - 72 hours fermentation incubator temperature $55^{\circ} \mathrm{C}$ and $72-120$ hours fermentation incubator temperature $35^{\circ} \mathrm{C}$. The results of oneway Anova analysis showed that the populations of $\mathrm{L}$. lactis and $A$. aceti in the initial inoculum addition treatment were significantly different $(p \leq 0.05)$ to the control. Population growth of $S$. cerevisiae, L. lactis and A. aceti produced in accordance with those obtained by [3]; who have studied the addition of $S$. cerevisiae (FNCC 3056), L. lactis (FNCC 0086) and A. aceti (FNCC 0016) in the fermentation process of fresh cocoa beans from the various varieties. The results of this study are also in accordance with the $r$ sults obtained by (Widianto, Pramita, \& Wedhastri, 2013) who studied the improvement of the fermentation process by adding cane drops and the addition of yeast, lactic acid bacteria and acetic acid bacteria. The results of this study indicate that the gradual treatment of S. cerevisiae, $L$. lactis and $A$. aceti populations at the beginning of fermentation was 8.66, 6.64 and $4.67 \mathrm{log}(\mathrm{cfu} / \mathrm{g})$, respectively. At 24 hours the fermentation of $S$. cerevisiae, $L$. lactis and A. aceti populations increased to 12.55, 8.23 and $5.53 \log (\mathrm{cfu} / \mathrm{g})$, respectively. At 48 hours fermentation of $\mathrm{S}$. cerevisiae, L. lactis and $A$. aceti populations, there were changes respectively, 6.54, 12.53 and $8.73 \mathrm{log}(\mathrm{cfu} / \mathrm{g})$. At 72 hours fermentation of $S$. cerevisiae, L. lactis and $A$. aceti populations were 3.87, 10.64 and $12.13 \log$ (cfu/g), respectively. Finally, the fermentation of S. cerevisiae, L. lactis and $A$. aceti populations decreased to 2.22, 6.23 and $9.22 \mathrm{log}$ $\mathrm{cfu} / \mathrm{g}$, respectively. The relationship between S. cerevisiae, L. lactis and $A$. aceti populations on the ethanol, lactic acid and acetic acid concentrations in the inoculum addition treatment is gradually presented in Figure 3 . 


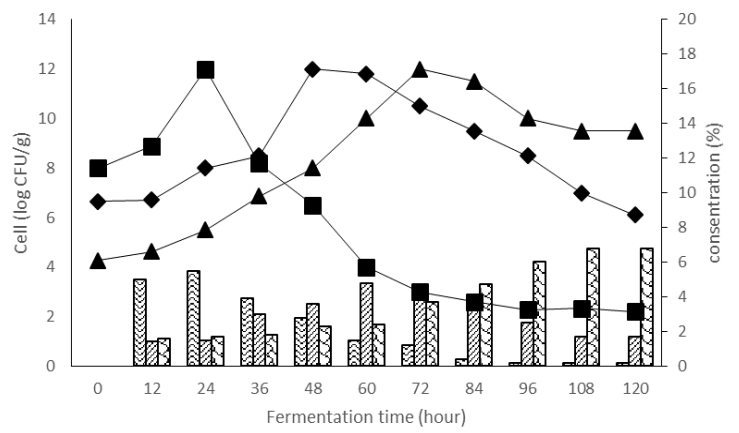

Figure 3.

Relationship of S. cerevisiae, L. lactis and A. aceti populations to the concentration of ethanol, lactic acid and acetic acid during the fermentation of cocoa beans resulting from the inoculum addition treatment. Initial (0) - 24 hours incubator temperature fermentation $35^{\circ} \mathrm{C}, 24-48$ hours fermentation incubator temperature $45^{\circ} \mathrm{C}, 48-72$ hours fermentation incubator temperature $55^{\circ} \mathrm{C}$ and $72-120$ hours fermentation incubator temperature $35^{\circ} \mathrm{C}$ The inoculum addition treatment gradually has the concentration of ethanol, lactic acid and acetic acid at the beginning of the whole fermentation of $0 \%$. At 24 hours of fermentation, the concentration of ethanol, lactan and acetic acid increased, respectively, 5.54, 1.55 and $1.70 \%$. At 48 hours of fermentation, the concentrations of ethanol, lactic acid and acetic acid were respectively 2.84 , 3.67 and $2.37 \%$. At 72 hours of fermentation the concentration of ethanol, lactic acid and acetic acid were shown at 1.23, 3.83 and $3.32 \%$, respectively, in line with the study of [13], that fermentation time would show an increase in organic acid compounds produce aroma compounds. The highest concentrations of ethanol, lactic acid and acetic acid occurred in 24,60 , and 108 hours of fermentation respectively, it can be assumed that the added inoculum underwent adaptation and competition with existing endogenous microbes. The results of one-way ANOVA analysis showed that the population of $\mathrm{S}$. cerevisiae, L. in the inoculum treatment was not significantly different from the control treatment and inoculum addition treatment simultaneously, while the population of L. lactis, A. aceti population was significantly different from the control. The treatment gradually addressed the average population of S. cerevisiae, L. lactis and A. aceti, respectively 5.66, 8.55 and $4.47 \log (\mathrm{cfu} / \mathrm{g})$. When viewed from the treatment variations of fermentation techniques showed the concentration of ethanol, lactic acid and acetic acid increased, it was assumed that the environmental temperature produced by the addition of inoculums which was $39-51^{\circ} \mathrm{C}$ was the optimum temperature for the activity of pectinolytic enzymes such as Poly Galactoranase (PG) enzymes and increased depolymerization of pulp Cocoa beans are in line with the results of the research of [11] who optimized the condition of depolymerization of cocoa bean pulp by enzymes that the optimum conditions for $\mathrm{PG}$ enzyme activity at a temperature of $42.5^{\circ} \mathrm{C}$ and $\mathrm{pH}$ 4.6. If viewed from the concentration of acetic acid produced, it can be interpreted that the treatment in stages is the best. Acetic acid is an organic acid that is diffused into seed pieces, resulting in the active enzyme polyphenol oxidase which oxidizes polyphenols

\section{CONCLUSION}

Rehydration of pulp can increase the moisture content of dried cocoa beans so that it can be used as a fermentation substrate. The quality of fermented cocoa beans can be improved through a controlled fermentation process. The treatment of adding inoculums gradually during fermentation can increase the fermentation temperature $\left(51{ }^{\circ} \mathrm{C}\right)$, fermentation index (1.03), reducing sugar content $(10.79 \%)$, percentage of the number of brown chips $(97.01 \%)$, acid concentration acetate $(6.83 \%)$, population of $S$. Cerevisiae (1012 cfu / g), L. lactis (1012 cfu / g) and A. aceti (1012 cfu / $\mathrm{g}$ ), although the $\mathrm{pH}$ of cocoa beans (4.22) is still low compared to control treatment and the addition of inoculum simultaneously fermentation.

\section{REFERENCES}

[1] W. U. Safitri, "Journal of Non Formal Education and Community Empowerment," J. Non Form. Educ. Community Empower., vol. 4, no. 1, pp. 71-78, 2015.

[2] A. C. Aprotosoaie, S. V. Luca, and A. Miron, "Flavor Chemistry of Cocoa and Cocoa Products-An Overview," Compr. Rev. Food Sci. Food Saf., vol. 15, no. 1, pp. 73-91, 2016.

[3] M. Apriyanto and E. Harmayani, "Study on effect of fermentation to the quality parameter of cocoa bean in Indonesia," Asian J. Dairy Food Res, vol. 35, no. 2, pp. 160-163, 2016.

[4] E. O. Afoakwa, J. E. Kongor, J. Takrama, and A. S. Budu, "Changes in nib acidification and biochemical composition during fermentation of pulp preconditioned cocoa (theobroma cacao) beans," Int. Food Res. J., vol. 20, no. 4, pp. 1843-1853, 2013.

[5] T. Romero-Cortes, "Isolation and characterization of acetic acid bacteria in cocoa fermentation," African J. Microbiol. Res., vol. 6, no. 2, pp. 339-347, 2012.

[6] M. Apriyanto, "Changes in Chemical Properties of Dreid Cocoa ( Theobroma cacao ) Beans during Fermentation," Intl. J. Food. Ferment. Technol, vol. 5, no. 1, pp. 11-16, 2016.

[7] M. E. Kustyawati and S. Setyani, "Pengaruh Penambahan Inokulum Campuran terhadap Perubahan Kimia dan Mikrobiologi selama Fermentasi Coklat," J. Teknol. Ind. dan Has. Pertan., vol. 13, no. 2, pp. 73-84, 2008.

[8] M. T. A. P. Kresnowati, L. Suryani, and M. Affifah, "Improvement of Cocoa Beans Fermentation by LAB Starter Addition," J. Med. Bioeng., vol. 2, no. 4, pp. 274-278, 2013.

[9] E. H. Mulono Apriyanto, Sutardi, Supriyadi, "Fermentasi biji kakao kering menggunakan Saccharomycescerevisiae , Lactobacillus lactis , Acetobacter aceti," AGRITECH, vol. 37, no. 3, pp. 302-311, 2017.

[10] E. O. Afoakwa, J. Quao, J. Takrama, A. S. Budu, and F. K. Saalia, "Chemical composition and physical quality characteristics of Ghanaian cocoa beans as affected by pulp pre-conditioning and fermentation," J. Food Sci. Technol., vol. 50, no. 6, pp. 1097-1105, 2013.

[11] G. Putra, Harijono, Susanto, Kumalaningsih, and Aulanni'am, "Optimasi kondisi depolimerisasi pulp biji kakao," J. Tek. Ind., vol. 9, no. 1, pp. 45-54, 2008.

[12] P. T. Tebu, D. A. N. B. Asam, D. Widianto, A. D. 
Pramita, and S. Wedhastri, "Perbaikan Proses Fermentasi Biji Kakao Kering Dengan," vol. 3, no. 1, 2013.

[13] J. Rodriguez-Campos, H. B. Escalona-Buendía, S. M. Contreras-Ramos, I. Orozco-Avila, E. JaramilloFlores, and E. Lugo-Cervantes, "Effect of fermentation time and drying temperature on volatile compounds in cocoa," Food Chem., vol. 132, no. 1, pp. 277-288, 2012. 